\title{
Exclusive Contracts in Health Insurance
}

\author{
Ilya Rahkovsky ${ }^{1}$ \\ ${ }^{1}$ Economic Research Service, USDA, Washington DC, USA \\ Correspondence: Ilya Rahkovsky, Economic Research Service, USDA, 1400 Independence Ave. SW, Washington, DC \\ 20250, USA. Tel: 1-202-694-5104. E-mail: irahkovsky@ers.usda.gov
}

Received: May 3, 2013

Accepted: June 12, 2013

Online Published: June 25, 2015

doi:10.5430/bmr.v4n2p37

URL: http://dx.doi.org/10.5430/bmr.v4n2p37

\begin{abstract}
Competition between insurance companies often increases the prices and reduces the availability of high quality health plans offered to employees. An insurance company can reduce competition by signing an exclusive contract, which guarantees that the company is the only insurance provider. This artcile shows whether exclusive contracts can alleviate the negative consequences of competition. Using the nation-wide survey of employers, I find that exclusive insurers charged less for a unit of insurance quality than non-exclusive insurers. Furthermore, I find that the pattern of insurance quality dispersion is consistent with the exclusive insurers offering more high quality plans.
\end{abstract}

Keywords: Health insurance, Exclusive contracts, Adverse selection, Monopoly, Competition

\section{Introduction}

Employers provide health insurance to the majority of Americans. When deciding on health coverage, employers must choose the number and quality of insurance plans to offer and whether to contract with one or multiple insurance companies. Economists often argue for competition between health plans or insurance providers is a way to increase the value of insurance. The competition may lead to lower prices (Ma and Browne, 2005; Bundorf, 2010; Vistnes, Cooper, \& Vistnes, 2001) and to overall welfare gains (Bundorf, Levin, Mahoney, \& Building, 2008; Ma and Browne, 2005). The downside of the competition is that the high quality plans tend to be provided at much higher price or not provided at all (Jack, 2001; Cutler and Reber, 1998; Frank, Glazer, \& McGuire,2000; Ellis and Aragao, 2001). Insurance companies often compete to attract healthier employees (Ellis, 1998) and they may be less likely to offer high quality plans where less healthy employees are concentrated (Frank et al., 2000). I am interested in whether a barrier to competition induce insurance companies to offer more higher quality plans for a lower premium.

Employers can construct a barrier to competition by signing exclusive contracts with insurance companies. Exclusive contracts guarantee that a single company is the only insurance provider for the employees in the firm. While there are many papers that study monopoly and competitive insurance markets starting from (Rothschild and Stiglitz, 1976), this paper is the first to study exclusive dealing arrangement between health insurer and employer. Exclusive insurers may be more likely to offer high quality plans because they are less likely to face entrants that may attract the healthier employees. Also, exclusive insurers can subsidize high quality plans if this subsidy is welfare enhancing (Jack, 2001; Barros, 2003; Glazer and McGuire, 2000).

I present a simple model of competition between health insurance plans offered in a firm. The model shows when subsidizing of the high quality plan increases total consumer surplus. Furthermore,the model predicts that firms with exclusive contracts are more likely to offer high quality plans, and that these high quality plans may be subsidized by insurance company - resulting in lower prices for these plans. I use the 1997 nation-wide survey of employers by the Robert Wood Johnson Foundation to study quality and price of health plans offered by exclusive and non-exclusive insurers. The survey collected information on the exclusivity of insurance contracts as well as extensive information on the quality of the health. I construct an index that measures the quality of plans to test whether the price of a unit of quality is different in the firms with and without exclusive contracts. Using this index I test the proposition that the firms with exclusive contracts are more likely to offer high quality plans by comparing the range of the quality of plans offered in these firms.

Empirical results support the model's predictions. For the firms with exclusive contracts the price of a unit of quality is 39-42 percent lower than for firms with no such contracts. Thus exclusive insurers charge lower prices for high quality plans. Furthermore, the quality of plans offered to firms with exclusive contracts is more diverse indicating that these firms may offer more high quality plans. These results show that employers and administrators of 
Medicare Advantage programs can use exclusive contracts to reduce price for high quality plans. Furthermore, antitrust authorities need to exercise caution when they investigate exclusive contracts in health insurance because these contracts can increase welfare.

\section{Background}

Prices for the employer-provided health insurance are set at the plan level. Insurance companies are forbidden from setting different prices for individual employees enrolled in the same plan. There are two factors that determine the price of a plan: the plan's quality (the amount of insurance the plan provides) and the average health status of the enrolled employees.

The concentration of high cost employees in high quality plans increases the prices for these plans and creates inefficiency by pricing out the medium cost employees out of these plans in the process of adverse selection (Frank et al., 2000). Even more troubling is the case when the distribution of medical expenditures is highly skewed to the right, then most of the employees in the firm may be priced out of the high quality plan by the very few high cost employees. (Note 1) As a result the consumer surplus of the employees who were priced out of the high quality plans is greatly reduced. Research of welfare losses from adverse selection produced mixed results. Cutler and Reber (1998) found significant welfare losses, while Einav, Finkelstein, Cullen, \& Building (2008) and Carlin and Town (2007) found that the losses were small.

A subsidy of the high quality plan can attract healthier employees to the plan and increase the total consumer surplus if the gain in the consumer surplus of the employees enrolled in the high quality plan will exceed the loss of the employees enrolled in the low quality plan. This subsidy is not possible if the competitor can enter the market and undercut the price of the subsidizing plan. (Note 2) Even if there is no cross-subsidization of the health plans, entrance can lead to a very unstable market and potential losses to the incumbent insurance company (Sutton, Feldman, and Dowd2004) because healthier employees have higher price elasticity of demand for health insurance (Royalty and Solomon, 1999; Stromborn, Buchmueller, \& Feldstein, 2002; Buchmueller and Feldstein, 1997). Exclusive contracts designed to protect insurance companies from entry can induce them to decrease the prices of the high quality plans.

A welfare maximizing pricing of the health plan can be achieved by employers who can find the optimal contribution toward the health insurance premium (Pauly and Herring, 2000). This solution may not work for all employers. For example, firms can vary in how much do their employees value a dollar contributed to a health coverage to a dollar paid as wages. Then an optimal contribution to address adverse selection may be smaller or larger than the contribution employees prefer based on their valuation of health insurance. Also, finding an optimal subsidy may be difficult for some employers because they do not know exactly how changes in contribution levels affect the selection of plans. Lastly, the cost of subsiding premiums is uncertain and insurance companies may be better prepared to bear this risk.

Exclusive contracts cannot completely prevent competition because an insurance contract can be dissolved at any time and exclusivity clause is not legally enforceable. Exclusive contracts state that the insurance company will offer specific coverage at a specific price as long as the company remains the sole provider of insurance. I interpret an exclusive contract as a credible signal sent by employers that they are interested in an exclusive relationship with the insurance company. This signal is not cheap for the employer to send. If the employer decides to add another insurer, the incumbent insurer will rescind the contract, imposing the costs on employees and the employer. Handel (2010) and Cebul, Rebitzer, Taylor, \& Votruba (2008) find large costs associated with switching insurance companies. Exclusive contacts may not eliminate the potential entry, but these contracts should decrease probability. Next I present the model to show how exclusive contracts between an employer and an insurer would work. For the literature on exclusive contracts between insurers and medical providers see (Lakdawalla and Sood, 2013), for the analysis of exclusive contracts in annuity market see (Rotschild, 2007)

\section{Model}

\subsection{Set Up}

The model needs to shows how a competition of insurance companies or lack thereof affect the sorting of employees between plans and a consumer surplus. Hence, in the model a firm offers two health plans. One plan provides basic coverage (low quality) and the other plan provides comprehensive coverage (high quality). Let $\theta$ denote the expected medical expenditures of an employee, where $\theta$ is uniformly distributed between 0 and 1 . The benefits employees derive from the plans are linear functions of $\theta$. The cost of insurance companies to provide the insurance plans is a linear function of the average $\theta$ of the employees enrolled in the plans $\left(\overline{\theta_{h}}, \overline{\theta_{l}}\right)$. I assume that the 
increase in the benefit from higher quality due to the marginal increase in $\theta$ is higher than the costs associated with this increase $(b>d)$.

$$
\begin{array}{ll}
\text { Benefit(High) } & =a+b \theta \\
\text { Cost }(\text { High }) & =c+d \overline{\theta_{h}} \\
\text { Benefit(Low) } & =e \theta \\
\text { Cost }(\text { Low }) & =f \overline{\theta_{l}}
\end{array}
$$

The willingness to pay for the high quality plan is an increasing function of $\theta$. At a given price for a high quality plan, there exists a $\hat{\theta}$ such that all employees with $\theta>\hat{\theta}$ choose the high quality plan and all employees with $\theta<\hat{\theta}$ choose the low quality plan. The price of the high quality plan reflects the average expenditures of the employees in the plan in the following way:

$$
P(\hat{\theta})=c+d E(\theta \mid \theta>\hat{\theta})=c+d(1+\hat{\theta}) / 2,
$$

provided $0<\hat{\theta}<1$. If the employee with $\theta=\hat{\theta}$ is indifferent between the two plans, we can explicitly find $\hat{\theta}$.

$$
\begin{aligned}
& \text { Benefit }(\hat{\theta})_{H}-\operatorname{Price}(\hat{\theta})_{H}=\text { Benefit }(\hat{\theta})_{L}-\operatorname{Price}(\hat{\theta})_{L} \\
& a+b \hat{\theta}-c-d(1+\hat{\theta}) / 2=e \hat{\theta}-0.5 f \hat{\theta} \\
& \hat{\theta}=(c-a+d / 2) /(b-e+0.5 f-0.5 d)
\end{aligned}
$$

\subsection{Subsidy and Equilibrium}

Prices under exclusive contracts may be different from the prices under non-exclusive arrangements (equation 2) when the entry is more likely. Under exclusive contract employees in the low quality plan can subsidize the employees in the high quality plan. Let $S$ be the total amount of subsidy for all employees enrolled in the high quality plan. The subsidy under the exclusive contract makes the high quality plan more attractive and some employees from the low quality switch to the high quality plan. Then there will be a new employee $\hat{\theta}^{e}$ indifferent between the two plans with smaller expected medical expenditures that the indifferent employee without the subsidy, i.e. $\hat{\theta}^{e}<\hat{\theta}^{c}$ (see Figure 1). The new indifferent employee is determined by:

$$
a+b \hat{\theta}^{e}-c-d\left(1+\hat{\theta}^{e}\right) / 2+S /\left(1-\hat{\theta}^{e}\right)=e \hat{\theta}^{e}-0.5 f \hat{\theta}^{e}-S / \hat{\theta}^{e} .
$$

The subsidy also increases the price of the low quality plan by $S / \hat{\theta}^{e}$, and it decreases the price of the high quality plan by $S /\left(1-\hat{\theta}^{e}\right)$ (see Figure 1). The subsidy $S$ may total consumer surplus if the gain of the employees in the high quality plan exceed the loss of the employees in the low quality plan though wider participation in the high quality plan.

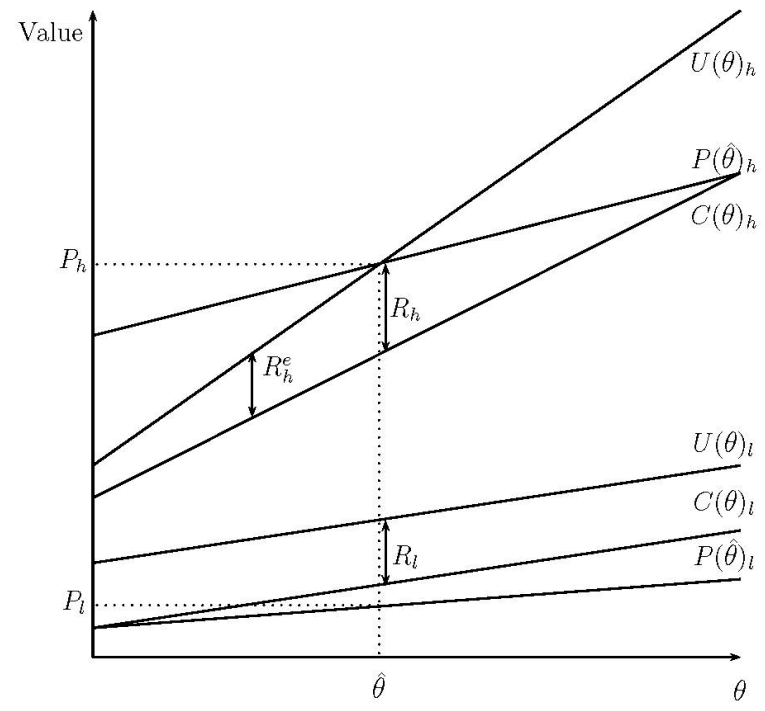

Figure 1. 


\subsection{Consumer Surplus}

The consumer surplus from the two plans is equal to the sum of benefits minus the price employees pay:

$$
\begin{gathered}
C S=\int_{\widehat{\theta}}^{1}\left(a+b \theta+\frac{S}{1-\widehat{\theta}}\right)-\int_{\widehat{\theta}}^{1}(c+d \theta)+\int_{0}^{\widehat{\theta}}\left((e-f) \theta-\frac{S}{\hat{\theta}}\right) \\
C S=0.5 \hat{\theta}^{2}(d-b+e-f)+\hat{\theta}(c-a)+a-c+0.5 b-0.5 d \\
\frac{\partial C S}{\partial S}=\frac{\partial C S}{\partial \widehat{\theta}} \frac{\partial \widehat{\theta}}{\partial S}=(c-a+\hat{\theta}(d-b+e-f)) \frac{\partial \widehat{\theta}}{\partial S}
\end{gathered}
$$

Proposition 1 There exist parameters $a, b, c, d, e, f$ such that the firm has a separating equilibrium and the subsidy of the high quality plan increases the consumer surplus. Proof in the Appendix.

$$
\left(e \hat{\theta}-f \hat{\theta}-(a+b \hat{\theta}-c-d \hat{\theta})=\left(\operatorname{Benefit}(\hat{\theta})_{L}-\operatorname{Cost}(\hat{\theta})_{L}\right)-\left(\operatorname{Benefit}(\hat{\theta})_{H}-\operatorname{Cost}(\hat{\theta})_{H}\right)<0\right.
$$

This result is shown on the figure 2. The subsidy increases welfare if the difference between the benefit $\theta=\hat{\theta}$ from the high quality plan and the cost of providing high quality plan to the employee $\left.\left(R_{h}\right)\right)$ exceeds the difference between benefits and costs from the low quality plan $\left(R_{l}\right)$. The reason why the employee cannot obtain higher surplus from the high quality plan is that the price of the plan exceeds the costs to provide the plan to the employee $\theta=\hat{\theta}$. A firm maximizes the total consumer surplus if it subsidizes the high quality plan while $R_{h}>R_{l}$. The subsidy equalizes the difference between the cost of benefit of the employee $\hat{\theta}$ in both plans. That results in a gain in the consumer surplus, see figure 2.

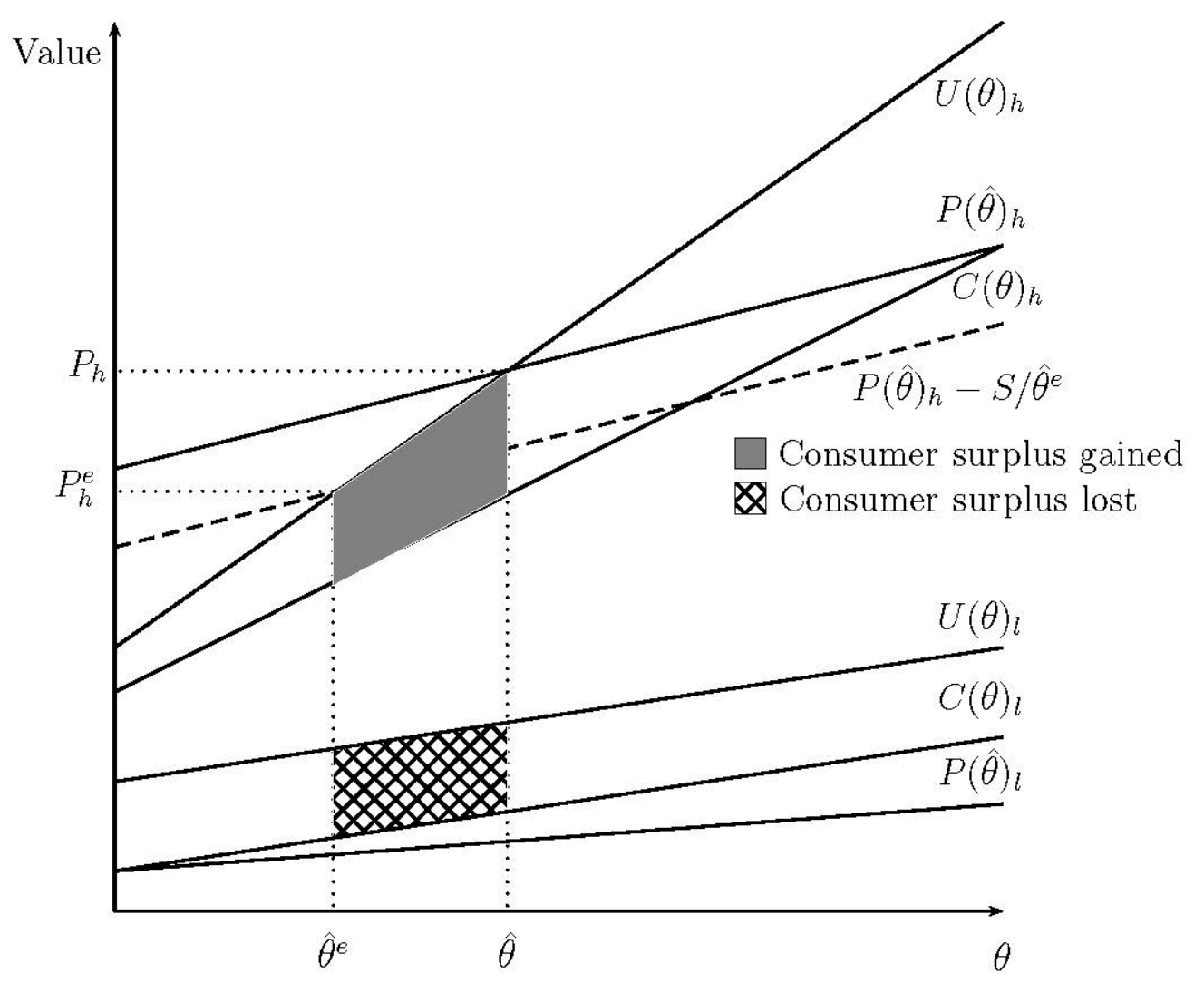

Figure 2. 


\subsection{Infeasibility of the High Quality Plan}

Employers may not be able to offer the high quality plan without a subsidy if the price of the high quality plan is equal to the willingness to pay for it at the point that lies outside of the distribution of $\theta$ (no single crossing), see figure 3.

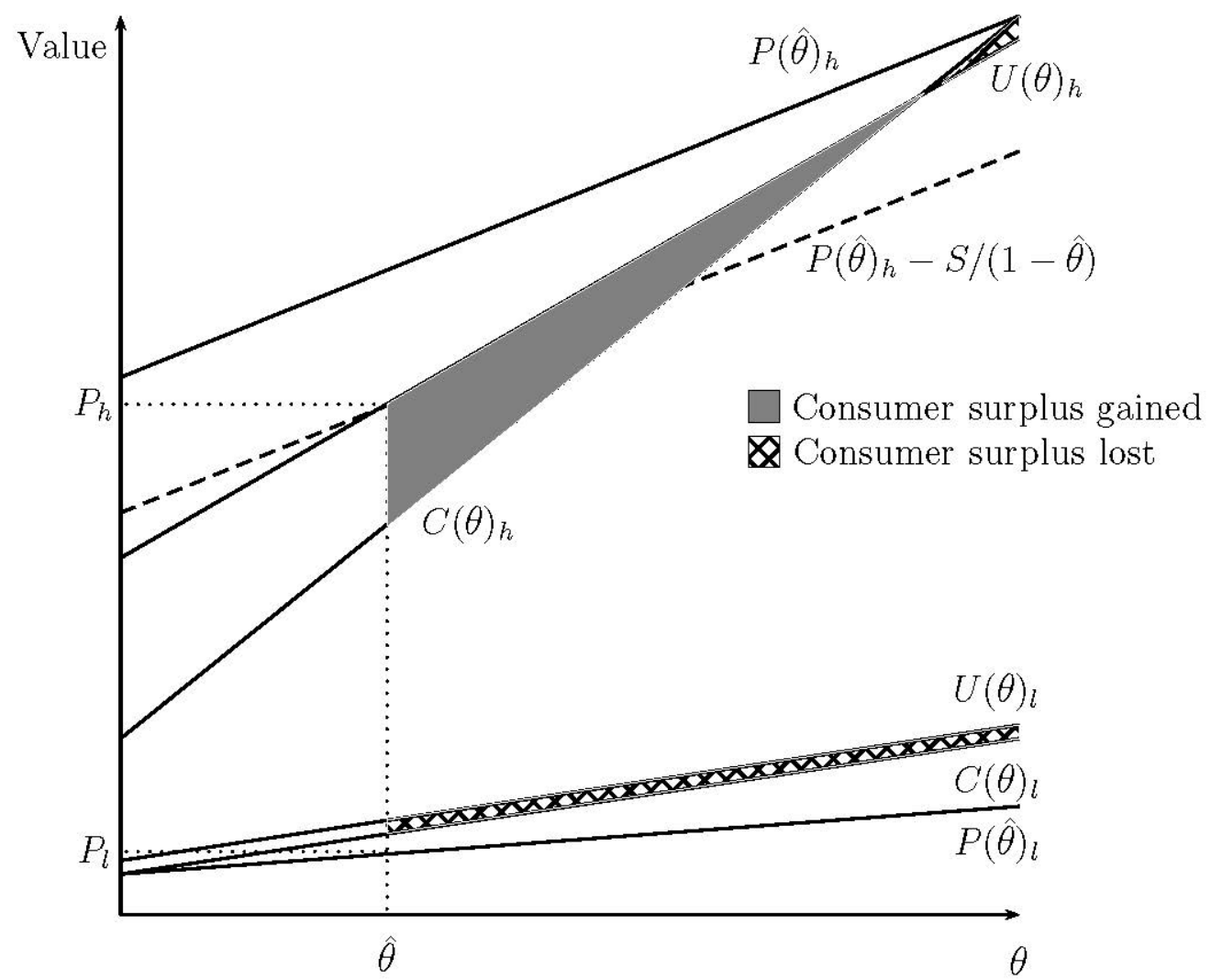

Figure 3.

Proposition 2 There exist parameters $a, b, c, d$, $e$ and $f$ such that the subsidy of the high quality plan increases the consumer surplus if no employee chooses the high quality plan without a subsidy. The sufficient conditions for this results are:

$$
a-c>b-d+f-e 2 b-1.5 d<2 e-1.5 f
$$

A subsidy of the otherwise infeasible high quality plan may increase consumer surplus if the employees with medium or low medical expenditures have sufficiently high consumer surplus from the high quality plan. The employees with high expenditures cannot pay for their own expenditures in the high quality plan - this is the root of its infeasibility. However, if a subsidy increases participation of the healthier employees they bring the average expenditures and premiums down making the high quality plan feasible. I model the subsidy as a transfer from the employees in low quality plan to the employee in the high quality plan. The subsidy has to be small enough to ensure the sufficient participation in the low quality plan.*

The subsidy decreases the price of the high quality plan and increases the price of the low quality plan. In addition, the subsidy attracts healthier employees to the high quality plan that further decreases its price. The subsidy is not possible without an exclusive contract because a competitor may offer the low quality plan at a lower price and lure the healthier employees.

\subsection{Empirical Predictions}

The model makes three empirical predictions. First, the relative price of the high quality plan in the firms with exclusive contracts is lower than in the firms with non-exclusive contracts. Second, the firms with exclusive contracts are more likely to offer high quality plans. Hence, I expect to see a larger range of quality among the plans offered in these firms. Third, an exclusive contract and subsidies it may involve increase total consumer surplus and would make insurance coverage more attractive. There will be some employees, were previously insured through the 
spouses, who will take up the insurance increasing the coverage rate.

\section{Data}

The Robert Wood Johnson Foundation conducted a survey of employers in the 48 contiguous states and the District of Columbia. This 1997 survey was based on geographical and firm size strata with random selection within each stratum. In the survey employers in the survey were asked about the health plans they offered. The unit of observation in the survey was a health plan. The survey asked whether a firm had an exclusive contract with an insurance company only when an employer offered more than one general medical plan. 3,203 firms (15,468 plans) provided information whether they had an exclusive contract with their insurance company.

My econometric specification requires that each firm should have non-missing plan control variables (deductables, copayments, etc) for at least two plans. After I dropped observations with missing control variables there are 1,913 firms $(10,257$ plans) left in the sample. Out of these firms $299(1,126)$ are self-insured. I dropped these firms because I consider a entry barrier to protect an incumbent insurance company, while in the self-insured firms there is no incumbent insurance company to protect. My final sample used for estimation is 1,604 firms (9,335 plans).

\subsection{Firms}

Table 1 presents the descriptive statistics of the firms with exclusive and non-exclusive insurers. The table provides information on 1,235 firms that is less than 1,635 firms used in estimation. The discrepancy is a result of the missing firm level variables that are presented in the descriptive statistics, although these variables are not used in estimation that features firm fixed effects. Firms with exclusive providers tend to have a slightly larger total number of employees, but a significantly smaller size of establishments than the firms with non-exclusive providers. The firms with non-exclusive providers have more female employees. However, the distributions of employees' wage, age and hours of work are similar. Firms with non-exclusive insurers offer a larger number of plans than the firms with non-exclusive insurer.

Table 1. Descriptive Statistics of Firm Level Variables

\begin{tabular}{lll}
\hline & Non-Exclusive & Exclusive \\
\hline Number of workers in establishment & $401.15^{*}$ & 164.43 \\
Total number of employees nationwide & $(1,505.8)$ & $(257.8)$ \\
& $2,619.5$ & $3,456.8$ \\
Temporary employees, \% & $(6,079.3)$ & $(7,374.6)$ \\
& 4.74 & 5.92 \\
Full time workers & $(12.74)$ & $(14.87)$ \\
& 79.13 & 81.99 \\
35-39 hr/wk workers & $(31.34)$ & $(29.55)$ \\
& 11.29 & 11.21 \\
30-34 hr/wk workers & $(25.48)$ & $(25.16)$ \\
Less than 20 hr/wk workers & $6.66^{* *}$ & 4.30 \\
Female workers & $(13.72)$ & $(9.33)$ \\
Less than \$5/hr workers & 2.93 & 2.51 \\
\$5-7/hr workers & $(9.57)$ & $(10.31)$ \\
& $48.53^{* * *}$ & 43.03 \\
Published by Sciedu Press & $(28.34)$ & $(29.11)$ \\
& 2.17 & 2.64 \\
& $(9.92)$ & $(10.22)$ \\
& 11.07 & 12.01 \\
& $(20.97)$ & $(21.63)$ \\
& & E-ISSN 1927-601X
\end{tabular}


$\$ 10-15 /$ hr workers

More than $\$ 15 / \mathrm{hr}$ workers

Less than 30 y.o workers

Union

Age of the firm

Turnover rate

[] Note: $* * *$ and $* * *$ indicate statistically significant difference in the means.

Numbers in the brackets are standard errors of the means.

\subsection{Plans}

Table 2 presents the descriptive statistics of the plan level variables for firms with and without exclusive contracts. Premium is a total monthly premium insurance companies charge the employer. Health plans offered in the firms with exclusive contracts cover slightly less services than the ones offered in the firms with non-exclusive providers. The former disclosure plans have longer waiting periods for the coverage of pre-existing conditions. The plans offered in the firms with exclusive providers also have higher deductables - dollar amount of the yearly claims that is not covered by the insurance company, along with higher copayments and coinsurance rates. Where copayment is a fixed dollar payment employees need to make each time they use a medical provider, and coinsurance is the percent of medical claim that is not covered by insurers. Plans with exclusive contracts are more likely to have maximum out-of-pocket payment that protect the insured against very large claims. 
Table 2. Descriptive Statistics of Health Plans

\begin{tabular}{|c|c|c|}
\hline & Non-Exclusive & Exclusive \\
\hline \multirow[t]{2}{*}{ Premium for single coverage } & $165.78 * *$ & 161.64 \\
\hline & $(41.34)$ & $(49.57)$ \\
\hline \multirow[t]{2}{*}{ Premium for family coverage } & 423.94 & 418.04 \\
\hline & $(90.79)$ & $(128.31)$ \\
\hline \multirow[t]{2}{*}{ Cover vision care } & $0.58 * *$ & 0.53 \\
\hline & $(0.49)$ & $(0.50)$ \\
\hline \multirow[t]{2}{*}{ Cover dental care } & $0.34 * * *$ & 0.20 \\
\hline & $(0.47)$ & $(0.40)$ \\
\hline \multirow[t]{2}{*}{ Enrollments in the plan } & 677.62 & 332.44 \\
\hline & $(5840.83)$ & $(2450.12)$ \\
\hline \multirow[t]{2}{*}{ Active employees enrolled in plan } & 490.11 & 271.56 \\
\hline & $(3570.34)$ & $(1766.09)$ \\
\hline \multirow[t]{2}{*}{ Waiting period, days } & $15.86^{* * *}$ & 53.06 \\
\hline & $(68.26)$ & $(118.20)$ \\
\hline \multirow[t]{2}{*}{ Deductable } & $26.21 * * *$ & 88.11 \\
\hline & $(97.48)$ & $(204.89)$ \\
\hline \multirow[t]{2}{*}{ Copayment } & $7.91 * * *$ & 9.37 \\
\hline & $(3.82)$ & $(3.64)$ \\
\hline \multirow[t]{2}{*}{ Coinsurance rate } & $15.81 * * *$ & 18.73 \\
\hline & $(7.65)$ & $(7.30)$ \\
\hline \multirow[t]{2}{*}{ Coinsurance vary for some services } & $0.85^{* * *}$ & 0.45 \\
\hline & $(0.36)$ & $(0.50)$ \\
\hline \multirow[t]{2}{*}{ Maximum out of pocket expense } & $0.64 * * *$ & 0.72 \\
\hline & $(0.48)$ & $(0.45)$ \\
\hline \multirow[t]{2}{*}{ HMO plan } & $0.72 * * *$ & 0.65 \\
\hline & $(0.45)$ & $(0.48)$ \\
\hline \multirow[t]{2}{*}{ POS plan } & 0.11 & 0.11 \\
\hline & $(0.31)$ & $(0.32)$ \\
\hline \multirow[t]{2}{*}{ PPO Plan } & $0.16^{* *}$ & 0.20 \\
\hline & $(0.37)$ & $(0.40)$ \\
\hline \multirow[t]{2}{*}{ Indemnity plan } & $0.01 * * *$ & 0.04 \\
\hline & $(0.10)$ & $(0.19)$ \\
\hline \multirow[t]{2}{*}{ Actuarial value of a plan } & 0.80 & 0.80 \\
\hline & 0.08 & 0.07 \\
\hline $\mathrm{N}$ & 8,922 & 413 \\
\hline
\end{tabular}

[] Note: $*, * *$ and $* * *$ indicate statistically significant difference in the means. Numbers in the brackets are standard errors of the means.

There are four major types of health plans offered to employees in the data set: Indemnity Plan, Health Maintenance Organization (HMO), Point of Service Plan (POS), and Preferred Provider Organization (PPO). These types vary in whether they restrict the choice of medical providers and utilization of medical services, see (Bundorf, 2002) for 
more information.

The main measure of insurance is the actuarial value of a plan. This value measures the share of the expected medical expenditures covered by the insurance. This variable was calculated by the designers of the survey in the following manner. First, they estimated expected medical expenditures of employees using the demographic information and geographical location. Then, they estimated the share of the expenditures covered by insurance linking expected medical expenditures with the insurance contract information. Actuarial value is bounded between 0 and 1 . For example, if an actuarial value is 0.77 , then $77 \%$ of the expected medical expenditures will be covered by the insurance. The actuarial values of the plans offered by exclusive and non-exclusive providers are similar. The last two lines provide descriptive statistics for the plan's quality predicted using firm fixed effects. The plans offered by exclusive providers tend to offer higher quality plans than the plans offered by non-exclusive providers for both single and family coverage.

\section{Price of Quality Estimation}

Quality of a plan has many parameters such as deductable, choice of providers, etc. The first step is to estimate the how these parameters contribute to the price of a plan by regressing the premium on the plan characteristics presented in the Table 1. The model shows that in the firms with exclusive contracts this relationship can be distorted by subsidies. Therefore firms with exclusive contracts are omitted because the goal of the first stage is to get a good measure how quality is related to price. (Note 3 )

The premium predicted using the coefficients estimated in this regression is an index of the plan's quality. There are some unobserved firm characteristics correlated with the premium such as distribution of health expenditures in the firm, administrative costs, prior experience, etc. I control for an unobserved firm heterogeneity using firm fixed effects. The regression equation is presented below:

$$
\text { Premium }_{j k}=\sum_{i=1}^{N} \hat{\delta} Q_{i j k}+u_{k}+e_{j k}
$$

where $u_{k}$ is a firm fixed effect. I use the coefficients estimated in the equation (9) to estimate the quality of plans for all firms:

$$
\widehat{Q} \text { uality }=\sum_{i=1}^{N} \hat{\delta} Q_{i j k}
$$

The model predicts that in the firms with exclusive contracts employees in low quality plans subsidize employees in the high quality plans. This subsidy increase the price of low quality plans and decreases the price of high quality plans in these firms. The model does not make explicit predictions about the firms that offer more than two plans, but I expect to see the price of a unit of insurance quality lower in the firms with exclusive contracts. To measure the price of a unit of quality I regress the price of the plans on the predicted quality with firm fixed effects in a hedonic regression. I use bootstrap procedure to estimate standard errors because the $\hat{Q}$ uality is a generated regressor.

$$
\begin{array}{r}
\text { Premium }_{j k}=\alpha_{1}+\beta_{1} \hat{Q}_{k} \text { uality }_{j k}+\beta_{2} \hat{Q} \text { uality }_{j k} \\
+v_{j k}
\end{array}
$$

The coefficient $\beta_{2}$ shows how much the price of a unit of quality is lower in the firms with exclusive contracts. I estimate the price of a unit of quality in the firms with exclusive contracts and in the firms without such contracts. Even if I find a lower price of a unit of quality in the firms with exclusive contracts this fact does not imply existences of subsidies. The subsidies result in a higher the price of low quality plans, but the use of the firm fixed effects prevents me from estimating the difference in the prices of low quality plans.

\subsection{Offer of High Quality Plans}

I test the propositions that the firms with exclusive contracts are more likely to offer high quality plans by comparing quality of the plans. The comparison of quality across firms is problematic because different firms are often charged different prices for the same plans (Cutler, 1994); a good quality for one firm may be a bad quality for the other. However, if firms with exclusive contracts can offer high quality plans and the firms without these contracts cannot, then the firms with exclusive contracts should have higher range of quality of the plans they offer. The range of 
quality is the difference between the plans with highest and lowest quality levels.

\section{Results}

In this section, I test the hypotheses that in the firms with exclusive contracts high quality plans have lower premiums than in the firms with no such contracts. In addition, I test whether the range of quality and the coverage rate in these firms are higher than in the firms without exclusive contracts.

\subsection{The Price of Quality}

Table 3 presents the estimated coefficients from linear regressions of price on predicted quality. The price of quality is lower in the firms with exclusive providers. In the firms with exclusive insurers the price of quality is 42 percentage points less than the price in the firms with non-exclusive insurers (coefficient is statistically significant at $5 \%$ level) for single coverage. (Note 4) As for the family coverage the firms with exclusive contracts have the price of quality 39 percentage points lower, although the coefficient is not statistically significant.

Table 3. Price of Quality Estimation

\begin{tabular}{|c|c|c|}
\hline & (1) & (2) \\
\hline \multirow[t]{2}{*}{$\bar{Q}$ uality } & $1.00 * * *$ & $1.00 * * *$ \\
\hline & $(.01)$ & $(.02)$ \\
\hline \multirow[t]{2}{*}{ Exclusive Provider $\times \hat{Q}$ uality } & $-.42 * *$ & -.39 \\
\hline & $(.2)$ & $(.29)$ \\
\hline \multirow[t]{2}{*}{ Const. } & 2.7 & 5.86 \\
\hline & $(2.64)$ & $(9.11)$ \\
\hline$R^{2}$ & .33 & .21 \\
\hline $\mathrm{N}$ & 9335 & 9316 \\
\hline Family & & $X$ \\
\hline Single & $\mathrm{X}$ & \\
\hline
\end{tabular}

[] Note: $*, * *$ and $* * *$ indicate statistical significance at $10 \%, 5 \%$ and $1 \%$ level. Standard errors are robust to heteroscedasticity. The standard errors are estimated using bootstrap procedure with 1000 replications.

\subsection{The Range of Quality}

In this subsection I present results from the estimation of the range of quality among the plans offered by firms. I constructed quality measures using firm fixed effects, thus the means of predicted quality are not influenced by firm characteristics. However, the number of plans a firm is likely to be positively correlated with the range of quality in a firm, although the exact nature of this relationship is difficult predict. (Note 5) 
Table 4. Means of the Range of Quality

\begin{tabular}{llll}
\hline & Range & Range & Coverage rate \\
\hline Firms with two plans & & & 67.6 \\
Non-Exclusive & 22.3 & 39.2 & 70.0 \\
Exclusive & $26^{* *}$ & $48.4^{* *}$ & 578 \\
$\mathrm{~N}$ & 770 & 770 & \\
Firms with three plans & & & 71.3 \\
Non-Exclusive & 22.8 & 43.3 & 70.1 \\
Exclusive & 18 & 35.2 & 293 \\
$\mathrm{~N}$ & 394 & 394 & 70.5 \\
Firms with four plans & & & 72.4 \\
Non-Exclusive & 23.5 & 45.1 & 151 \\
Exclusive & 27.8 & 53.2 & 73.9 \\
$\mathrm{~N}$ & 197 & 197 & 73.1 \\
Firms with five plans & & & 85 \\
Non-Exclusive & 23.9 & 49.2 & \\
Exclusive & 22 & 42.3 & \\
$\mathrm{~N}$ & 124 & 124 & $\mathrm{X}$ \\
Family & & $\mathrm{X}$ & \\
Single & & & \\
\hline IN & & & \\
\hline
\end{tabular}

[] Note: $*, * *$ and $* * *$ indicate statistical significance difference between means at $10 \%, 5 \%$ and $1 \%$ level. Standard errors are estimated using bootstrap procedure with 1000 replications robust to heteroscedasticity.

Table 4 presents ranges of quality offered and the coverage rates in the firms with two to five plans. Among the firms that offer two health plans, the range of quality in the firms with exclusive contracts is higher (statistically significant difference at $5 \%$ level) than in the firms with no exclusive contracts. For the single coverage the difference in the range of quality is $\$ 4.2$ ( $23 \%$ of one s.d. for the group), and for the family coverage the difference is $\$ 9.2(25 \%$ of one s.d. for the group). Among the firms that offer more than two plans the difference between the ranges of quality is not significant. The model in the section 3 predicts that exclusive contracts increase the range of quality only for the firms with two plans and for the single coverage plans in the firms with four plans. The effects of the exclusive contracts on the firms with more than two plans depends on the market segmentation of these plans. The difference in the coverage rate between the firms with and without exclusive contracts is insignificant.

\section{Robustness Checks}

The model considers the firms that offer only two health plans, so it is important to make sure that the results from these firms support the model's predictions. Table 5 shows the regression results for the firms that offer only two plans. The magnitudes of the estimated coefficients are similar to those in the Table 3. The standard errors of the estimated coefficients are expectedly larger because of the smaller sample size. 
Table 5. Price of Quality for Firms with Two Plans

\begin{tabular}{lll}
\hline & $(1)$ & $(2)$ \\
\hline Q̂uality & $1.00 * * *$ & $1.00 * * *$ \\
Exclusive Provider $\times$ Quality & $(.13)$ & $(.18)$ \\
& -.31 & -.55 \\
Const. & $(.34)$ & $(.61)$ \\
& 3.2 & 26.4 \\
$R^{2}$ & $(19.2)$ & $(74.4)$ \\
N & .18 & .09 \\
Family & 1,259 & 1,245 \\
Single & & $\mathrm{X}$ \\
\hline
\end{tabular}

[] Note: $* * *$ and $* * *$ indicate statistical significance at $10 \%, 5 \%$ and $1 \%$ level. Standard errors are robust to heteroscedasticity. The standard errors are estimated using bootstrap procedure with 1000 replications. In the estimation all firms with more than 2 plans were dropped.

Table 6. Mean Employers' Payments for Insurance

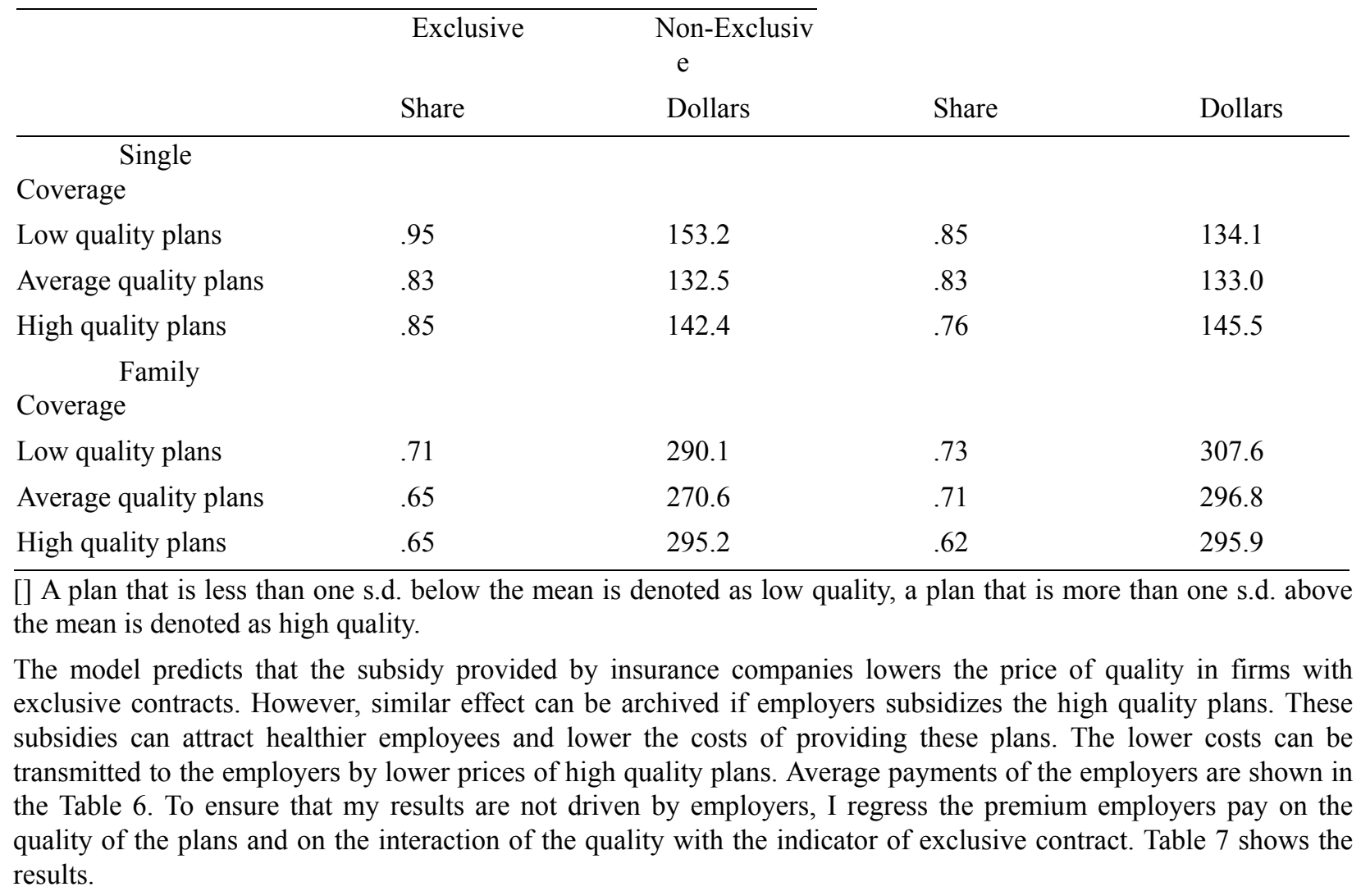


Table 7. Employers' Payments and Quality of Plans

\begin{tabular}{lll}
\hline & $(1)$ & $(2)$ \\
\hline Q̂uality & $0.24 * * *$ & $0.13 * * *$ \\
& $(.01)$ & $(.02)$ \\
Exclusive Provider $\times$ Q̂uality & .09 & 0.18 \\
& $(.15)$ & $(0.31)$ \\
Const. & $94.85 * * *$ & $237.77 * * *$ \\
& $(2.36)$ & $(8.32)$ \\
$R^{2}$ & .05 & .01 \\
$\mathrm{~N}$ & 9,335 & 9,316 \\
Family & & $\mathrm{X}$ \\
Single & $\mathrm{X}$ & \\
\hline
\end{tabular}

[] Note: $* * *$ and $* * *$ indicate statistical significance at $10 \%, 5 \%$ and $1 \%$ level. Standard errors are robust to heteroscedasticity. The standard errors are estimated using bootstrap procedure with 1000 replications.

Employers with exclusive contracts subsidize high quality slightly more than the employers with no such contracts, although the estimates are very noisy. Even if we assume that these estimates are correct they are still very small to drive the results. Employers with exclusive contracts subsidize a unit of quality in family and single plans by 9 and 18 percent more than the employers without these contracts. This small subsidy is not likely to account for the whole 39-42 percent discount for a unit of quality that firms with exclusive contracts receive from insurance companies.

Table 8. Self-Insured Firms and Exclusive Contracts

\begin{tabular}{lll}
\hline & $(1)$ & $(2)$ \\
\hline & $.96^{* * *}$ & $.91^{* * *}$ \\
Exclusive Provider & $(.02)$ & $(.04)$ \\
& $-.28^{*}$ & -.30 \\
Self-Insured & $(.17)$ & $(.25)$ \\
& -.03 & $-.03^{*}$ \\
Const. & $(.02)$ & $(.02)$ \\
& $8.8^{* * *}$ & $44.2^{* *}$ \\
& $(2.9)$ & $(17.8)$ \\
$\mathrm{N}$ & .28 & .16 \\
Family & 10,257 & 10,238 \\
Single & & $\mathrm{X}$ \\
\hline
\end{tabular}

[] Note: $*, * *$ and $* * *$ indicate statistical significance at $10 \%, 5 \%$ and $1 \%$ level. Standard errors are robust to heteroscedasticity. The standard errors are estimated using bootstrap procedure with 1000 replications.

Self-insured firms were dropped from the primary estimation because the model considered the competition between insurance companies. However, these self-insured firms are interesting because they have more control over the design of insurance then firms purchasing insurance from the market. Self-insured firms can decrease the prices of the high quality plans if they consider it to be beneficial. In Table 8, self-insured firms are considered as a separate category, to see if the price of a unit of quality in these firms is different from the firms without exclusive contracts. I find the price of a unit of quality in the self-insured firms to be 3 percentage points lower than the fully insured firms with no exclusive contracts. This is a very small difference relative to estimated 30 percentage points difference in the firms with exclusive contacts suggesting that perhaps self-insured firms do not subsidize high quality plans. 


\section{Conclusion}

This paper is the first to consider exclusive contracts between employers and insurance companies. Even though exclusive contracts are legally unenforceable they have significant effect on the price of insurance. I find that in the firms with exclusive contracts the relative prices for high quality plans are lower than in the firms with no such contracts. I also find that the firms with exclusive contracts and two health plans have larger range of quality indicating that these firms offer more higher quality plans.

In the model the high quality plans are cheaper in the firms with exclusive contracts because it is optimal to subsidize them. This argument can be seen in another way - it is risky to offer high quality plans if the entry is likely, because an entrant may attract healthier employees from an incumbent insurer. Alternative explanation of the exclusive contracts may be that they can lower administrative or fixed costs insurance companies have to incur. However the lowering of fixed costs should not affect the difference between the premiums of high and low quality plans. And thus it should not affect the results of regression.

Much of the existing economic research focused on the costs of and benefits of allowing competition between health insurance plans. Researchers found that competition is a good tool for employer to lower the costs of insurance, but competition is also associated with the decrease in the quality of the plans. In this paper, I show that there is a tool for employers who want to lower the price of high quality plans - exclusive contract with insurance company. In addition, exclusive contracts can be used by administrators of Medicare Advantage program who contract with private health plans to provide services more than 10 million people (Berenson and Dowd, 2009).

The results of the paper are also important for the ongoing discussion on welfare implications of exclusive contracts. The attitudes of antitrust authorities toward exclusive contracts varied overtime, but they were generally more lenient toward these contracts than the academic economists (Lafontaine and Slade, 2005; Segal and Whinston, 2000). I show that exclusive contracts between health insurance companies and employers can increase welfare supporting the lenient attitude of antitrust authorities.

The major limitation of the paper is that I cannot identify exact mechanism that drives the variation in prices of high and low quality plans. The lower prices for high quality plans in the firms with exclusive contracts can be driven by a cross-subsidy, where employees in low quality plans subsidize employees in high quality plans. Alternatively, exclusive contracts can lower the probability of entry and decrease the expected costs of insurance companies. The lower costs can be transmitted to employers via lower prices. In this paper, I broadly define when the subsidization of the high quality plan increases consumer surplus and makes it optimal for a firm to sign the exclusive contract with an insurer. The question why exclusive contracts increase consumer surplus for some firms and not for others requires a more specific answer.

\section{Appendix}

Proof of Proposition 1.

$$
\frac{\partial C S}{\partial S}=\frac{\partial C S}{\partial \widehat{\theta}} \frac{\partial \widehat{\theta}}{\partial S}=(c-a+\hat{\theta}(d-b+e-f)) \frac{\partial \widehat{\theta}}{\partial S}
$$

The subsidy of the high quality plan makes increases enrollment in the plan, hence $\frac{\partial \widehat{\theta}}{\partial S}<0$. There are two Cases possible for in the separating equilibrium:

Case I:

$$
\begin{array}{ll}
a-c-0.5 d & >0 \\
e-0.5 f-b+0.5 d & >0 \\
e+0.5 d-0.5 f-b & >a-c-0.5 d
\end{array}
$$

The change in the consumer surplus increases in $b$. Maximum $b$ subject to the constraints 13 approach to $c-a+d-e-0.5 f$. Then: 


$$
\begin{aligned}
\frac{\partial \hat{\theta}}{\partial S} & =(c-a+\hat{\theta}(d-b+e-f) \\
& =(c-a+\hat{\theta}(a-c-0.5 f) \\
& <(\hat{\theta}-1)(a-c) \\
& <0
\end{aligned}
$$

If $\frac{\partial \widehat{\theta}}{\partial S}<0$ then $\frac{\partial C S}{\partial S}>0$.

Case II

$$
\begin{array}{ll}
a-c-0.5 d & <0 \\
e-0.5 f-b+0.5 d & <0 \\
e+0.5 d-0.5 f-b & <a-c-0.5 d
\end{array}
$$

The change in the consumer surplus decreases in $c$. Minimum $c$ subject to the constraints 15 approaches $a-d+b-e+0.5 f$. Then:

$$
\begin{aligned}
\frac{\partial \widehat{\theta}}{\partial S} & =(c-a+\hat{\theta}(d-b+e-f) \\
& =(-d+b-e+0.5 f+\hat{\theta}(d-b+e-f) \\
& <(-0.5 d+b-e+0.5 f+\hat{\theta}(0.5 d-b+e-0.5 f) \\
& <(\hat{\theta}-1)(0.5 d-b+e-0.5 f) \\
& <0
\end{aligned}
$$

Therefore for both cases there are exists parameters $a, b, c, d, e$, and $f$ such that $\frac{\partial C S}{\partial S}>0$.

Proof of the Proposition 2. If the high quality plan is infeasible then even the sickest employee would choose to purchase the low quality plan:

$$
\begin{array}{ll}
a+b-c-0.5 d & <e-0.5 f \\
e-0.5 f & >0
\end{array}
$$

The difference in the total consumer surplus if both plans are offered versus only low quality plan is:

$$
\begin{aligned}
\Delta C S & =C S(\text { twoplans })-C S(\text { oneplan }) \\
& =0.5 \hat{\theta}^{2}(d-b+e-f)+\hat{\theta}(c-a)+a-c+0.5 b-0.5 d-0.5 e+0.5 f \\
& =(1-\hat{\theta})(a-c)+0.5\left(1-\hat{\theta}^{2}\right)(b-d+f-e)
\end{aligned}
$$

$\triangle C S$ is positive if

$$
a-c>b-d+f-e
$$

Plugging constraint leads to the following constraints:

$$
a-c>b-d+f-e 2 b-1.5 d<2 e-1.5 f
$$

There exist parameters that satisfy constraints above if $(a-c)$ is sufficiently larger than then $(b-d)$. For example the values $\mathrm{a}=0.5, \mathrm{c}=0.1, \mathrm{~d}=0.1, \mathrm{~d}=0.3, \mathrm{f}=0.2$ and $\mathrm{e}=0.3$ will fit the constraints.

\section{References}

Barros, P. (2003). Cream-skimming, incentives for efficiency and payment system. Journal of Health Economics, 22(3):419-443. http://dx.doi.org/10.1016/S0167-6296(02)00119-4

Berenson, R. \& Dowd, B. (2009). Medicare advantage plans at a crossroads-yet again. Health Affairs, 28(1):w29.doi:10.1377/hlthaff.28.1.w29 
Buchmueller, T. C. \& Feldstein, P. J. (1997). The effect of price on switching among health plans. Journal of Health Economics, 16(2):231 - 247. http://dx.doi.org/10.1016/S0167-6296(96)00531-0

Bundorf, M. (2010). The effects of offering health plan choice within employment-based purchasing groups. Journal of Risk and Insurance, 77(1):105-127. http://dx.doi.org/10.1111/j.1539-6975.2009.01338.x

Bundorf, M., Levin, J., Mahoney, N., \& Building, L. (2012). Pricing and welfare in health plan choice. American Econmic Review.102(7): 3214-48. http://dx.doi.org/10.1257/aer.102.7.3214

Bundorf, M. K. (2002). Employee demand for health insurance and employer health plan choices. Journal of Health Economics, 21:65-88. http://dx.doi.org/10.1016/S0167-6296(01)00127-8

Cardon, J. H. \& Hendel, I. (2001). Asymmetric information in health insurance: Evidence from national medical expenditures survey. RAND Journal of Economics, 32(3):408-427. http://dx.doi.org/10.2307/2696362

Carlin, C. and Town, R. (2007). Adverse selection, welfare and optimal pricing of employer sponsored health plans. U. Minnesota Working Paper.

Cebul, R., Rebitzer, J., Taylor, L., \& Votruba, M. (2008). Unhealthy insurance markets: Search frictions and the cost and quality of health insurance. NBER Working Paper.

Cutler, D. (1994). Market failure in the small group insurance. NBER Working Paper.

Cutler, D. \& Reber, S. (1998). Paying for health insurance: The trade-off between competition and adverse selection. Quarterly Journal of Economics, 113(2):433-466. http://dx.doi.org/10.1162/003355398555649

deVen, W. P. M. M. V. \& Praag, B. M. S. V. (1981). The demand for deductibles in private health insurance : A probit model with sample selection. Journal of Econometrics, 17(2):229 - 252. http://dx.doi.org/10.1016/0304-4076(81)90028-2

Diehr, P., Yanez, D., Ash, A., Hornbrook, M., \& Lin, D. (1999). Methods for analyzing health care utilization and costs. Annual Review of Public Health, 20(1):125-144. http://dx.doi.org/10.1016/0304-4076(81)90028-2

Duan, N. (1983). Smearing estimate: a nonparametric retransformation method. Journal of the American Statistical Association, pages 605-610. http://dx.doi.org/10.1080/01621459.1983.10478017

Einav, L., Finkelstein, A., Cullen, M., and Building, L. (2008).Estimating welfare in insurance markets using variation in prices. NBER Working Paper.

Ellis, R. (1998). Creaming, skimping and dumping: provider competition on the intensive and extensive margins. Journal of Health Economics, 17(5):537-555. http://dx.doi.org/10.1016/S0167-6296(97)00042-8

Ellis, R. \& Aragao, F. (2001). Death spirals, switching costs, and health premium payment systems. Technical report, mimeo (Boston University).

Frank, R. G., Glazer, J., \& McGuire, T. G. (2000).Measuring adverse selection in managed health care. Journal of Health Economics, 19(6):829-854. http://dx.doi.org/10.1016/S0167-6296(00)00059-X

Glazer, J. \& McGuire, T. (2000). Optimal risk adjustment in markets with adverse selection: an application to managed care. American Economic Review, pages 1055-1071. http://dx.doi.org/10.1257/aer.90.4.1055

Handel, B. (2010). Adverse selection and switching costs in health insurance markets: When nudging hurts. manuscript, Northwestern University.

Jack, W. (2001). Controlling selection incentives when health insurance contracts are endogenous. Journal of Public Economics, 80(1):25-48. http://dx.doi.org/10.1016/S0047-2727(00)00103-1

Lakdawalla, Darius, \& Sood, Neeraj (2013). Health Insurance as a two-part pricing contract. Journal of Public Economics, 102:1-12. http://dx.doi.org/10.1016/j.jpubeco.2013.03.001

Lafontaine, F. \& Slade, M. (2005). Exclusive contracts and vertical restraints: Empirical evidence and public policy. Handbook of Antitrust Economics, Paolo Buccirossi (Ed.),Cambridge: MIT Press, Forthcoming.

Ma, Y.-L. \& Browne, M. (2005). Subsidization and choice in the group health insurance market. Journal of Risk \& Insurance, 72(3):413-439. http://dx.doi.org/10.1111/j.1539-6975.2005.00131.x

Pauly, M. \& Herring, B. (2000). An efficient employer strategy for dealing with adverse selection in multiple-plan offerings: an MSA example. Journal of Health Economics, 19(4):513-528.31. http://dx.doi.org/10.1016/S0167-6296(00)00049-7 
Rothschild Casey (2007). Adverse selection, linear pricing and front-loading in annuity markets. Working paper. [Online] Available: http://www.econ.kuleuven.ac.be/public/ndaaa08/caseyrothschild2007.pdf

Rothschild, M. \& Stiglitz, J. (1976). Equilibrium in Competitive Insurance Markets: An Essay on the Economics of Imperfect Information. Quarterly Journal of Economics, 90(4):629-649. http://dx.doi.org/10.1016/S0167-6296(00)00049-7

Royalty, A. \& Solomon, N. (1999). Health plan choice: Price elasticities in a managed competition setting. The Journal of Human Resources, 34(1):1-41. http://dx.doi.org/10.1016/S0167-6296(01)00124-2

Segal, I. \& Whinston, M. (2000). Exclusive contracts and protection of investments. RAND Journal of Economics, 31(4):603-633. http://dx.doi.org/10.2307/2696351

Stromborn, B., Buchmueller, T., \& Feldstein, P. J. (2002). Switching costs, price sensitivity and health plan choice. Journal of Health Economics, 21(1):89-116. http://dx.doi.org/10.1016/S0167-6296(01)00124-2

Sutton, H., Feldman, R., \& Dowd, B. (2004). Disruption of a managed competition environment by low-ball premium bids: The Minnesota State Employees Group Insurance Program. North American Actuarial Journal, $8(2): 45-55$.

Vistnes, J. P., Cooper, P. F., \& Vistnes, G. S. (2001). Employer contribution methods and health insurance premiums: Does managed competition works? International Journal of Health Care Finance and Economics, 1:159-187. http://dx.doi.org/10.1023/A:1012878628161

\section{Notes}

Note 1. Medical costs in the US population are well approximated by a log-normal distribution that is skewed to the right (Cardon and Hendel, 2001; Duan, 1983; de Ven and Praag, 1981; Diehr et al., 1999).

Note 2. In the telephone interview a sales representative of an insurance company said that his company demands exclusive contract because the company is afraid that the plan they offer will be adversely selected against and exclusivity allows them to have sufficient participation rate (telephone interview, June 15, 2009).

Note 3. The omitted variables are the indicators whether a plan covers physicians, hospital use, mental health treatments, indicator of gatekeeper physician, squared coinsurance, squared copayment, squared deductable, and a third degree polynomial of actuarial value.

Note 4 . The average price of quality is by construction 100 percentage points.

Note 5. To understand the exact relationship between the range of quality and the number of plans offered in a firm one needs to model competition between multiple plans that is beyond the scope of this paper. 